\title{
予見サーボ系の設計と一般化予測制御（GPC）システムについて
}

\author{
江上 正 $^{*}$ 土 谷 武 士**.愛 田一 雄*** \\ 北 森 俊 行****
}

\section{Preview Servo System Design and Relation with GPC System}

\author{
Tadashi EgAmi*, Takeshi TsuchiYA**, \\ Kazuo AIDA*** and Toshiyuki KITAMORI****
}

\begin{abstract}
Generalized Predictive Control (GPC) utilizing information on predicted future controlled variables of the controlled object has been proposed and has become of major interest. Some points are left unclear, for example, relation between the control system performance and the parameters of performance index employed has not been cleared in the GPC system and the GPC system is not always stable.

In this paper, preview servo system design method for the ARMAX by means of principle of optimality is proposed. This system is always guaranteed to be stable, and desirable number of preview steps and asymptotical properties of the control system are theoretically derived.

Using the result of this preview servo system, GPC system is constructed by means of principle of optimality.

Relation between the preview servo system and GPC system is examined to obtain properties of the preview servo system as compared with GPC system.
\end{abstract}

Key Words : GPC, preview servo system, principle of optimality, ARMAX model

\section{1. まえがき}

近年，プロセス制御の分野において，目標値の未来値 を利用するモデル予測制御が注目され，実プラントへの 応用も広く行われるようになっている1). 現在応用され ている代表的なアルゴリズムは, MAC (Model Algorithmic Control), DMC (Dynamic Matrix Control)な どである。これらのアルゴリズムでは，プラントモデル

†第 13 回 Dynamical System Theory シンポジウムで発 表 $(1991 \cdot 1)$

* 神奈川大学工学部 横浜市神奈川区六角橋 3-27-1

** 北海道大学工学部 札幌市北区北 13 条西 8

$* * *$ 新潟大学工学部 新潟市五十嵐 2 の町 8050

**** 東京大学工学部 東京都文京区本郷 7-3-1

* Faculty of Engineering, Kanagawa University, Yokohama

** Faculty of Engineering, Hokkaido University, Sapporo

*** Faculty of Engineering, Niigata University, Niigata

**** Faculty of Engineering, University of Tokyo, Bunkyo-ku, Tokyo

(Received May 1, 1991)

(Revised November 27, 1991)
の予測出力をインパルス応答やステップ応答を使って表 現しており，プラントの動特性を直観的に捉えやすいと いう利点がある.しかし，このモデルはかなり多くのサ ンプル数で表現しなければならないため, 制御則が長く なり，その計算に時間がかかると共に，計算機も大きな 記憶容量を要するという久点もある.

これに対して, ARMAX (Auto-Regressive MovingAverage Exogeneous) (ARX) モデルは，同定の際にそ の次数を決定しなければならないという煩わしさはある が，少ないパラメータで表現できるので制御則が簡単に なり，その計算時間と計算機の記憶容量が大幅に減少で きるという長所がある.

D. W. Clarke ら 2) 4) は最近, ARMAX モデルに対し てステップ状外乱を想定して表現したCARIMA (Controlled Auto-Regressive Integrated MovingAverage）モデルを用いる GPC (Generalized Predictive Control）を提案し，注目を集めている。この GPC は未来目標値を利用してプラントの制御性能を改善しよ うとする一種のディジタル予見制御である. しかし，設 計の評価関数に使われる多くの設計パラメータと設計さ 
江上・土谷・愛田・北森：予見サーボ系の設計と一般化予測制御（GPC）システムについて

れた制御系の特性との関係が明確でなく, 制御系が安定 になるように設計パラメータの選択に考慮が必要である という好ましくない性質ももっている4). 未来目標值を 利用する予見制御系としては最適性の原理を用いた予見 サーボ系5)なども提案されており, GPCシステムとの関 係についての考察などは興味深いテーマと思われる.

本論文ではまず CARIMA モデルで表わされた 1 入出 カプラントに対して, GPCで用いる評価関数に終端項を 付加した評価関数を用いて最適性の原理を用いた予見サ 一ボ系を構成する。構成された制御系は常に安定となり, 必要な予見ステップ数や評価関数の重みに対する制御系 の漸近特性なども明らかになる。これは上述の GPCの 好ましくない性質を回避した一つの設計法になってい る.つぎにこの結果において終端項を零とした場合から GPCを最適性の原理を用いて誘導する。これによって GPC と予見サーボ系の比較が可能となり, GPCなどの モデル予測制御が日本をはじめとした多くの研究者によ って扱われてきた予見制御と同類のものであることを明 らかとする.また，これにより GPCの評価関数に使われ る設計パラメータと制御系の性質の関係を明らかにする ための手がかりをあたえる. 最後にシミュレーションに より本論文で提案する予見サーボ系の性質について検討 を行う。

\section{CARIMA モデルを用いた予見サーボ系の 設計}

\section{1 制御 対 象}

制御対象として次式の CARIMA モデルで表わされる 1 入出力線形プラントを考える.

$$
A\left(z^{-1}\right) y(k)=B\left(z^{-1}\right) z^{-L_{m}} u(k-1)+d(k)
$$
ただし，

$$
\begin{aligned}
& A\left(z^{-1}\right)=1+a_{1} z^{-1}+\cdots+a_{n} z^{-n} \\
& B\left(z^{-1}\right)=b_{0}+b_{1} z^{-1}+\cdots+b_{m} z^{-m}
\end{aligned}
$$

ここで, $m \leqq n-1, L_{m} \geqq n-m-1$ であり, $A\left(z^{-1}\right)$ と $B\left(z^{-1}\right)$ は互いに既約であるとする。また $d(k)$ はステッ プ外乱などを考慮して $d(k)=\eta(k) / \Delta(\eta(k)$ : 無相関なラ ンダム系列, $\left.\Delta: 1-z^{-1}\right)$ とする

以下は (1)式で表わされるプラントに対して, (4)式 の評価関数のもと, 最適な操作量を求めるものを予見制 御，（1 式で表わされるプラントに対して，(29)式の評 価関数のもと, 最適な操作量を求めるものを GPC と定 義する。

いま( 1 )式はつぎのように状態方程式表現できる.

$$
\begin{aligned}
& \tilde{\boldsymbol{x}}(k+1)=\tilde{\boldsymbol{A}} \tilde{\boldsymbol{x}}(k)+\tilde{\boldsymbol{B}} u(k)+\tilde{\boldsymbol{d}}(k) \\
& y(k)=\tilde{\boldsymbol{C}} \tilde{\boldsymbol{x}}(k)
\end{aligned}
$$

ここで, $\tilde{\boldsymbol{x}}(k)$ は $\left(n+m+L_{m}\right) \times 1$ ベクトル, $\tilde{\boldsymbol{A}}$ および
$\tilde{\boldsymbol{B}}, \tilde{\boldsymbol{C}}$ は以下に示すような行列扔よびベクトルである.

$$
\begin{gathered}
\tilde{\boldsymbol{x}}(k)=\left[\begin{array}{ll}
y(k) \cdots y(k-n+1) & u\left(k-L_{m}-m\right) \cdots \\
u(k-1)
\end{array}\right]^{T} \\
\tilde{\boldsymbol{d}}=\left[\begin{array}{cccc}
d(k) & 0 & \cdots \cdots & 0
\end{array}\right]^{T}
\end{gathered}
$$

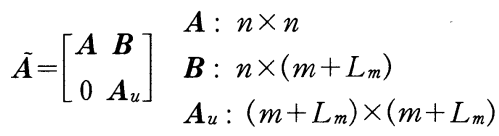

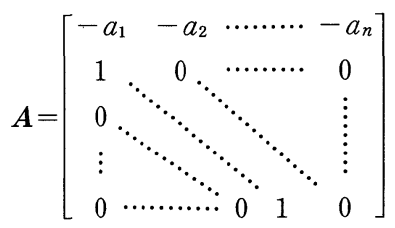
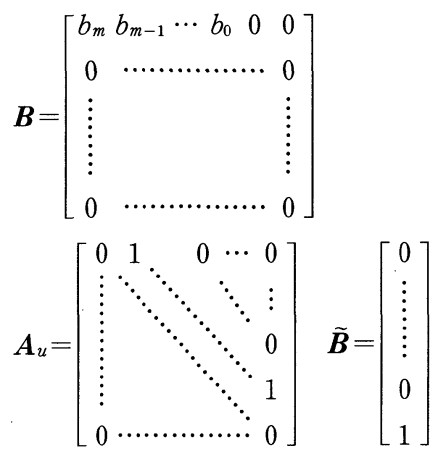

$\widetilde{\boldsymbol{C}}=\left[\begin{array}{llll}1 & 0 & \cdots & 0\end{array}\right]$

ただし， $L_{m}=0$ のときは $\boldsymbol{B}$ および $\tilde{\boldsymbol{B}}$ は

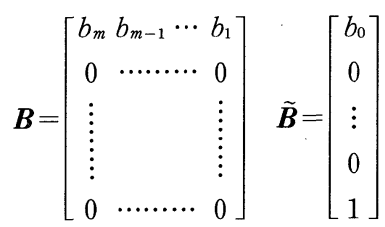

となる。

( 2 )式において $(\tilde{\boldsymbol{A}}, \tilde{\boldsymbol{B}})$ は可制御であり, $(\tilde{\boldsymbol{C}}, \tilde{\boldsymbol{A}})$ は可 検出となる.

ここで, 差分演算子 $\Delta=1-z^{-1}$ を導入するとつぎのよ うな拡大系が構成される。このとき $d(k)$ は零として扱 える。

$$
\begin{aligned}
{\left[\begin{array}{c}
y(k+1) \\
\Delta \tilde{\boldsymbol{x}}(k+1)
\end{array}\right]=} & {\left[\begin{array}{cc}
1 & \tilde{\boldsymbol{C}} \tilde{\boldsymbol{A}} \\
0 & \tilde{\boldsymbol{A}}
\end{array}\right]\left[\begin{array}{c}
y(k) \\
\Delta \tilde{\boldsymbol{x}}(k)
\end{array}\right] } \\
& +\left[\begin{array}{c}
\tilde{\boldsymbol{C}} \tilde{\boldsymbol{B}} \\
\tilde{\boldsymbol{B}}
\end{array}\right] \Delta u(k)
\end{aligned}
$$

ただし，

$$
\begin{aligned}
& L_{m} \geqq 1 \text { のとき } \tilde{\boldsymbol{C}} \widetilde{\boldsymbol{B}}=0 \\
& L_{m}=0 \text { のとき } \widetilde{\boldsymbol{C}} \widetilde{\boldsymbol{B}}=b_{0}
\end{aligned}
$$

これを以下のように表わす.

$$
\boldsymbol{x}_{0}(k+1)=\hat{\boldsymbol{A}} \boldsymbol{x}_{0}(k)+\tilde{\boldsymbol{B}} \Delta u(k)
$$

また

$$
y(k)=\left[\begin{array}{llll}
1 & 0 & \cdots & 0
\end{array}\right] \boldsymbol{x}_{0}(k)=\hat{\boldsymbol{C}} \boldsymbol{x}_{0}(k)
$$


(1) 式において $B\left(z^{-1}\right)$ が $z=1$ に根をもたなければ, (3) 式において $(\hat{\boldsymbol{A}}, \hat{\boldsymbol{B}})$ は可制御であり, $(\hat{\boldsymbol{C}}, \hat{\boldsymbol{A}})$ は可検 出となる. 以下では $(3)$ 式の系は可制御, 可検出である とする。

\section{2 予見サーボ系構成}

いま現在時刻を $k$ とするとき，現在から $N$ ステップ 未来までの目標值信号が既知である場合を考え，つぎの ような評価関数 $J$ を定義する.

$$
\begin{aligned}
J= & {\left[\boldsymbol{R}_{0}(k+N)-\boldsymbol{x}_{0}(k+N)\right\}^{T} \boldsymbol{H} } \\
& \times\left\{\boldsymbol{R}_{0}(k+N)-\boldsymbol{x}_{0}(k+N)\right\} \\
& +\sum_{j=1}^{N}\left[\left\{\boldsymbol{R}_{0}(k+j)-\boldsymbol{x}_{0}(k+j)\right\}^{T} \widehat{\boldsymbol{C}}^{T} \widehat{\boldsymbol{C}}\right. \\
& \left.\times\left\{\boldsymbol{R}_{0}(k+j)-\boldsymbol{x}_{0}(k+j)\right\}+\rho \Delta u(k+j-1)^{2}\right]
\end{aligned}
$$

ただし， $R(k+j)$ は目標値信号であり，

$$
\begin{aligned}
\boldsymbol{R}_{0}(k+N) & \triangleq\left[\begin{array}{ll}
R(k+N) & 0 \cdots 0
\end{array}\right]^{T} \\
& =\widehat{\boldsymbol{C}}^{T} R(k+N)
\end{aligned}
$$

$\boldsymbol{H}:$ 半正定対称行列

$$
\rho: \text { 正実数 }
$$

である.この評価関数と GPCの設計に使われる評価関 数との大きな違いは右辺第 1 項の終端項が含まれている ことである。

( 4 )式の評価関数を最小にするような制御入力は最適 性の原理を用いて以下のように求められる ${ }^{5)}$. 評価関数 の $[k+j, k+N]$ における最小值を $\min J_{N-j}$ とすると, 最適性の原理を適用することによって次式を得る。

$$
\begin{aligned}
\min J_{N-j}= & \min _{\Delta u(k+j)}\left[\left\{\boldsymbol{R}_{0}(k+j+1)-\boldsymbol{x}_{0}(k+j+1)\right\}^{T}\right. \\
& \times \widehat{\boldsymbol{C}}^{T} \widehat{\boldsymbol{C}}\left\{\boldsymbol{R}_{0}(k+j+1)-\boldsymbol{x}_{0}(k+j+1)\right\} \\
& \left.+\rho \Delta u(k+j)^{2}+\min J_{N-j+1}\right]
\end{aligned}
$$

ここで $\min J_{N-j}$ をつぎのように仮定する.

$$
\begin{aligned}
\min J_{N-j}= & \boldsymbol{x}_{0}^{T}(k+j) \boldsymbol{\Lambda}(N-j) \boldsymbol{x}_{0}(k+j) \\
& +\boldsymbol{\Theta}^{T}(N-j) \boldsymbol{x}_{0}(k+j)+\phi(N-j)
\end{aligned}
$$

ここで,

$$
\begin{aligned}
& \boldsymbol{\Lambda}(N-j):\left(n+m+L_{m}\right) \times\left(n+m+L_{m}\right) \text { 正定行列 } \\
& \boldsymbol{\Theta}(N-j):\left(n+m+L_{m}\right) \times 1 \text { ベクトル } \\
& \phi(N-j): \text { スカラー值 }
\end{aligned}
$$

(6)式を(5)式に代入して計算を進めると (6)式の仮定 に矛盾はなく $\Delta u(k)$ の最適值は次式のように求められ る.

$$
\begin{aligned}
\Delta u(k)= & -D(N) \hat{\boldsymbol{B}}^{T} \boldsymbol{S}(N-1) \hat{\boldsymbol{A}} \boldsymbol{x}_{0}(k) \\
& +D(N) \hat{\boldsymbol{B}}^{T} \hat{\boldsymbol{C}}^{T} R(k+1) \\
& -\frac{1}{2} D(N)^{-1} \hat{\boldsymbol{B}}^{T} \boldsymbol{\Theta}(N-1)
\end{aligned}
$$

ここで,

$$
\begin{aligned}
\boldsymbol{S}(N-j)= & \hat{\boldsymbol{A}^{T}} \boldsymbol{S}(N-\overline{j+1}) \hat{\boldsymbol{A}} \\
& -\hat{\boldsymbol{A}}^{T} \boldsymbol{S}(N-\bar{j}+1) \hat{\boldsymbol{B}} D(N) \hat{\boldsymbol{B}}^{T} \boldsymbol{S}(N
\end{aligned}
$$

$$
\begin{gathered}
-\overline{j+1}) \hat{\boldsymbol{A}}+\hat{\boldsymbol{C}}^{T} \hat{\boldsymbol{C}} \\
D(N-j)=\left[\rho+\hat{\boldsymbol{B}}^{T} \boldsymbol{S}(N-\overline{j+1}) \hat{\boldsymbol{B}}\right]^{-1} \\
\boldsymbol{\Theta}^{T}(N-j)= \\
\quad\left\{\boldsymbol{\Theta}^{T}(N-\overline{j+1})-2 R(k+\overline{j+1}) \hat{\boldsymbol{C}}\right\} \\
\quad \times \boldsymbol{\xi}(N-\overline{j+1}) \\
\boldsymbol{\xi}(N-\overline{j+1})=\hat{\boldsymbol{A}}-\hat{\boldsymbol{B}} D(N-j) \hat{\boldsymbol{B}}^{T} \boldsymbol{S}(N-\overline{j+1}) \hat{\boldsymbol{A}} \\
\quad(j=N-1, N-2, \cdots, 1)
\end{gathered}
$$

であり, 境界条件は

$$
\begin{aligned}
& \boldsymbol{S}(0)=\boldsymbol{H}+\widehat{\boldsymbol{C}}^{T} \widehat{\boldsymbol{C}} \\
& D(1)=\left[\rho+\widehat{\boldsymbol{B}}^{T} \boldsymbol{S}(0) \hat{\boldsymbol{B}}\right]^{-1} \\
& \boldsymbol{\Theta}^{T}(0)=-2 R(k+N) \hat{\boldsymbol{C}} H
\end{aligned}
$$

となる。（10)式から $\boldsymbol{\Theta}^{T}(N-1)$ を求め $(7)$ 式に代入する と(12)式のようになる.

$$
\begin{aligned}
\Delta u(k)=- & D(N) \hat{\boldsymbol{B}}^{T} \boldsymbol{S}(N-1) \hat{\boldsymbol{A}} \boldsymbol{x}_{0}(k) \\
+ & D(N) \widehat{\boldsymbol{B}}^{T}\left[\hat{\boldsymbol{C}}^{T}, \boldsymbol{\xi}^{T}(N-2) \hat{\boldsymbol{C}}^{T},\right. \\
& \boldsymbol{\xi}^{T}(N-2) \boldsymbol{\xi}^{T}(N-3) \hat{\boldsymbol{C}}^{T}, \cdots, \\
& \left.\boldsymbol{\xi}^{T}(N-2) \cdots \boldsymbol{\xi}^{T}(0)[\boldsymbol{H}+\boldsymbol{I}] \widehat{\boldsymbol{C}}^{T}\right] \overline{\boldsymbol{R}}(k)
\end{aligned}
$$

ただし，

$$
\overline{\boldsymbol{R}}(k) \triangleq[R(k+1), R(k+2), \cdots, R(k+N)]^{T}
$$

( 8 ) 式の Riccati 方程式は, $(\hat{\boldsymbol{C}}, \hat{\boldsymbol{A}})$ が可検出なので半 正定一意解 $\boldsymbol{P}$ をもち, 重み行列 $\boldsymbol{H}$ を $\boldsymbol{H}=\boldsymbol{P}-\widehat{\boldsymbol{C}}^{T} \widehat{\boldsymbol{C}}$ と すると, $\boldsymbol{S}(i)=\boldsymbol{P}(i=0,1, \cdots, N-1), D(i)=D(i=1, \cdots$, $N-1), \boldsymbol{\xi}(i)=\boldsymbol{\xi}(i=0,1, \cdots, N-2)$ と一定值となる.これ らを(12)式に代入すると(13)式のようになる.

$$
\begin{aligned}
\Delta u(k)= & -D \widehat{\boldsymbol{B}}^{T} \boldsymbol{P} \hat{\boldsymbol{A}} \boldsymbol{x}_{0}(k) \\
+ & D \widehat{\boldsymbol{B}}^{T}\left[\hat{\boldsymbol{C}}^{T}, \boldsymbol{\xi}^{T} \widehat{\boldsymbol{C}}^{T},\left(\boldsymbol{\xi}^{T}\right)^{2} \hat{\boldsymbol{C}}^{T}, \cdots,\right. \\
& \left.\quad\left(\boldsymbol{\xi}^{T}\right)^{N-1} \boldsymbol{P} \hat{\boldsymbol{C}}^{T}\right] \overline{\boldsymbol{R}}(k) \\
= & \boldsymbol{F}_{x} \boldsymbol{x}_{0}(k)+\boldsymbol{F}_{R} \overline{\boldsymbol{R}}(k)
\end{aligned}
$$

(13)式において

$$
\boldsymbol{F}_{x}=\left[f_{y} f_{x 0} \cdots f_{x \overline{n-1}} f_{u L \overline{m+m}} \cdots f_{u 1}\right]
$$

とおくと(14)式が得られる。

$$
\begin{aligned}
\Delta u(k)= & \boldsymbol{F}_{x} \boldsymbol{x}_{0}(k)+\boldsymbol{F}_{R} \overline{\boldsymbol{R}}(k) \\
= & {\left[f_{y} f_{x 0} \cdots f_{x \overline{n-1}} f_{u L \overline{m+m}} \cdots f_{u 1}\right] \boldsymbol{x}_{0}(k)+\boldsymbol{F}_{R} \overline{\boldsymbol{R}}(k) } \\
= & \left(f_{y}+f_{x 0}\right) y(k)+\cdots \\
& +\left(f_{x \overline{n-1}}-f_{x \overline{n-2}}\right) y(k-n+1)-f_{x \overline{n-1}} y(k-n) \\
& +f_{u 1} \Delta u(k-1)+\cdots+f_{u L \overline{m+m}} \Delta u\left(k-L_{m}\right. \\
& -m)+\boldsymbol{F}_{R} \overline{\boldsymbol{R}}(k) \\
= & \boldsymbol{F}_{R} \overline{\boldsymbol{R}}(k)+\boldsymbol{F}_{y} \overline{\boldsymbol{y}}(k)+\boldsymbol{F}_{u} \overline{\boldsymbol{u}}(k) \\
\overline{\boldsymbol{y}}(k) \triangleq & {[y(k), y(k-1), \cdots, y(k-n)]^{T} } \\
\overline{\boldsymbol{u}}(k) \triangleq & {\left[\Delta u(k-1), \Delta u(k-2), \cdots, \Delta u\left(k-L_{m}-m\right)\right]^{T} }
\end{aligned}
$$

(14)式が ARMAX モデルから作成した状態空間モデル に対する予見サーボ系の制御入力となる．ここで以下の ような変数を定義する。

$$
\begin{aligned}
& \boldsymbol{M}_{R}(z) \triangleq\left[z, z^{2}, \cdots, z^{N}\right]^{T} \\
& \boldsymbol{M}_{y}\left(z^{-1}\right) \triangleq\left[z^{-1}, z^{-2}, \cdots, z^{-n}\right]^{T}
\end{aligned}
$$




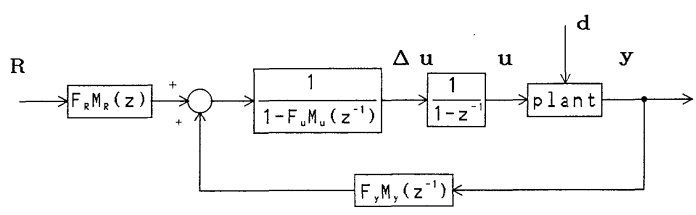

Fig. 1 Block diagram of preview servo system

$$
\boldsymbol{M}_{u}\left(z^{-1}\right) \triangleq\left[z^{-1}, z^{-2}, \cdots, z^{-(L m+m)}\right]
$$

これらの変数を用いて(14)式をブロック線図で表わすと

Fig.1のようになる.

\section{3 (4) 式の評価関数の意義}

(4) 式の評価関数において終端項の重み $\boldsymbol{H}$ を $\boldsymbol{H}=\boldsymbol{P}$ $-\hat{\boldsymbol{C}}^{T} \hat{\boldsymbol{C}}$ とすると,有限区間で定義される評価関数にもか かわらず, 状態フィードバック係数行列 $\boldsymbol{F}_{x}$ が Riccati 方程式の半正定一意解 $\boldsymbol{P}$ によって与えられ, 常に安定な 制御系が設計できる.

このようにすることによって評価関数の意義があいま いになるようにみえる。しかし，(3)式の拡大系に対し て (4) 式の評価関数を用いて得た (13)式の予見サーボ系 の制御則は, 無限区間で定義された評価関数

$$
\begin{aligned}
& J_{0}=\sum_{i=h}^{\infty}\left\{e^{2}(i)+\rho \Delta u^{2}(i)\right\} \\
& e(i) \triangleq y(i)-R(i)
\end{aligned}
$$

を用いて設計する有限予見動作をもつ予見サーボ系の制 御則(6) と等価になることを示すことができる(付録参 照). (15) 式の評価関数は, GPC の設計に使われる評価関 数の最大評価ホライズンを無限大にした形とであり, そ の意義は明白である。

\section{4 予見サーボ系の定常ロバスト性}

Fig. 1 の制御系の定常ロバスト性について証明を行 う.

いま(14)式のフィードバック係数行列 $\boldsymbol{F}_{y}$ および予見 フィードフォワード係数行列 $\boldsymbol{F}_{R}$ を

$$
\begin{aligned}
& \boldsymbol{F}_{R}=\left[f_{R 1}, f_{R 2}, \cdots, f_{R N}\right] \\
& \boldsymbol{F}_{y}=\left[f_{y 0}, f_{y 1}, \cdots, f_{y n}\right]
\end{aligned}
$$

のように表現し， $\gamma$ を

$$
\gamma \triangleq \sum_{i=1}^{N} f_{R i}
$$

と定義する. $k \geqq l の k て ゙$ 目標值信号 $R(k)$ が定值 $R^{*} に$ なるものと仮定すると, $k \geqq l$ で Fig. 1 のブロック図は

Fig. 2 と等価になる.

ここで( 8 ) 式に対する定常 Riccati 方程式を $\boldsymbol{\xi}$ を用い て表現すると

$$
\boldsymbol{P}=\boldsymbol{\xi}^{T} \boldsymbol{P} \hat{\boldsymbol{A}}+\widehat{\boldsymbol{C}}^{T} \hat{\boldsymbol{C}}
$$

が得られる.両辺にP $\boldsymbol{P} \hat{A}$ を加え, $\left(\boldsymbol{I}-\boldsymbol{\xi}^{T}\right)$ が正則として整 理すると

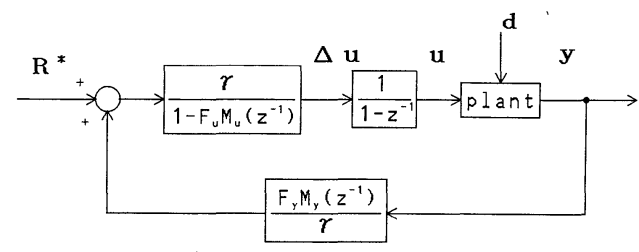

Fig. 2 Equivalent block diagram in $j \geqq l$

$$
\boldsymbol{P} \hat{\boldsymbol{A}}=\left(\boldsymbol{I}-\boldsymbol{\xi}^{T}\right)^{-1} \boldsymbol{P}(\hat{\boldsymbol{A}}-\boldsymbol{I})+\left(\boldsymbol{I}-\boldsymbol{\xi}^{T}\right)^{-1} \widehat{\boldsymbol{C}}^{T} \widehat{\boldsymbol{C}}
$$
となる.ここで $\hat{A}, \hat{C}$ の定義式をつぎのように表現する.

$$
\hat{A}=\left[\begin{array}{ll}
\hat{C}^{T} & A_{1}
\end{array}\right], \widehat{C}=\left[\begin{array}{ll}
1 & 0_{n+m+L_{m}}
\end{array}\right]
$$
ただし，

$$
\boldsymbol{A}_{1} \triangleq\left[\begin{array}{c}
\tilde{\boldsymbol{C}} \tilde{\boldsymbol{A}} \\
\tilde{\boldsymbol{A}}
\end{array}\right], 0_{n+m+L_{m}}: 1 \times\left(n+m+L_{m}\right) \text { の零ベクトル }
$$

(19)式の表現を用いると(18)式は

$$
\begin{aligned}
& \boldsymbol{P}\left[\widehat{C}^{T} A_{1}\right]=\left(I-\boldsymbol{\xi}^{T}\right)^{-1} \boldsymbol{P}\left[\begin{array}{ll}
0 & A_{2}
\end{array}\right] \\
& +\left(\boldsymbol{I}-\boldsymbol{\xi}^{T}\right)^{-1} \widehat{\boldsymbol{C}}^{T}\left[\begin{array}{ll}
1 & \mathbf{0}_{n+m+L_{m}}
\end{array}\right]
\end{aligned}
$$

$\boldsymbol{A}_{2}: \hat{\boldsymbol{A}}-\boldsymbol{I}$ によって得られる $\left(n+m+L_{m}+1\right) \times(n$ $\left.+m+L_{m}\right)$ の行列

となる.この第 1 項目の等式から

$$
\boldsymbol{P} \widehat{\boldsymbol{C}}^{T}=\left(\boldsymbol{I}_{n+m+L m}-\boldsymbol{\xi}^{T}\right)^{-1} \widehat{\boldsymbol{C}}^{T}
$$

が成り立つ. (16)式の $\gamma$ は

$$
\begin{aligned}
\gamma= & D \widehat{\boldsymbol{B}}^{T}\left\{\boldsymbol{I}+\boldsymbol{\xi}^{T}+\cdots+\left(\boldsymbol{\xi}^{T}\right)^{N-2}+\left(\boldsymbol{\xi}^{T}\right)^{N-1} \boldsymbol{P}\right] \widehat{\boldsymbol{C}}^{T} \\
= & D \widehat{\boldsymbol{B}}^{T}\left\{\left(\boldsymbol{I}-\left(\boldsymbol{\xi}^{T}\right)^{N-1}\right)\left(\boldsymbol{I}-\boldsymbol{\xi}^{T}\right)^{-1} \widehat{\boldsymbol{C}}^{T}\right. \\
& \left.+\left(\boldsymbol{\xi}^{T}\right)^{N-1} \boldsymbol{P} \widehat{\boldsymbol{C}}^{T}\right\}
\end{aligned}
$$

となるが，(21)式の関係を用いると

$$
\begin{aligned}
\gamma & =D \widehat{\boldsymbol{B}}^{T}\left(\boldsymbol{I}-\boldsymbol{\xi}^{T}\right)^{-1} \widehat{\boldsymbol{C}}^{T} \\
& =D \widehat{\boldsymbol{B}}^{T} \boldsymbol{P} \widehat{\boldsymbol{C}}^{T}
\end{aligned}
$$

となる。一方,

$$
\begin{aligned}
{\left[\boldsymbol{F}_{y} \boldsymbol{M}_{y}\left(z^{-1}\right)\right]_{z=1} } & =\sum_{i=0}^{n} f_{y i} \\
& =f_{y} \\
& =-D \widehat{\boldsymbol{B}}^{T} \boldsymbol{P} \hat{\boldsymbol{A}} \widehat{\boldsymbol{C}}^{T} \\
& =-D \widehat{\boldsymbol{B}}^{T} \boldsymbol{P} \widehat{\boldsymbol{C}}^{T}
\end{aligned}
$$

が得られる。元に, (23), (24) 式から, $\gamma=$ - $\left[\boldsymbol{F}_{y} \boldsymbol{M}_{y}\left(z^{-1}\right)\right]_{z=1}$ となるので, $k \rightarrow \infty て ゙$ Fig. 2 の制御系 は直結フィードバックとなり, 内部モデルの原理を満足 する.したがって, Fig. 1 の制御系は全系の安定性が損な われない範囲のプラントパラメータの変動䇽よびステッ プ状のプラント外乱に対しても定常偏差は残らず, 定常 ロバストであることがわかる。

なお (4) 式の評価関数において $N$ を無限大とすると (13)式の予見フィードフォワード係数行列は

$$
D \widehat{\boldsymbol{B}}^{T}\left[\widehat{\boldsymbol{C}}^{T}, \boldsymbol{\xi}^{T} \widehat{\boldsymbol{C}}^{T},\left(\boldsymbol{\xi}^{T}\right)^{2} \widehat{\boldsymbol{C}}^{T}, \cdots\right]
$$

となる。ここで $(k+N+1)$ ステップ以降の目標值信号を すべて $R(k+N)$ に等しいとして, $R(k+j)(j \geqq N)$ が定 
9601992 年 8 月

值 $R^{*}$ のときの予見フィードフォワード項は

$$
\begin{gathered}
D \widehat{\boldsymbol{B}}^{T}\left[\widehat{\boldsymbol{C}}^{T} R(k+1)+\boldsymbol{\xi}^{T} \widehat{\boldsymbol{C}}^{T} R(k+2)\right. \\
+\cdots+\left(\boldsymbol{\xi}^{T}\right)^{N-2} \widehat{\boldsymbol{C}}^{T} R(k+N-1) \\
\left.+\left\{\left(\boldsymbol{\xi}^{T}\right)^{N-1}+\left(\boldsymbol{\xi}^{T}\right)^{N}+\cdots\right\} \widehat{\boldsymbol{C}}^{T} R^{*}\right]
\end{gathered}
$$

となるが，(21)式の関係を用いると

$$
\begin{aligned}
& \left\{\left(\boldsymbol{\xi}^{T}\right)^{N-1}+\left(\boldsymbol{\xi}^{T}\right)^{N}+\cdots\right\} \widehat{\boldsymbol{C}}^{T} R^{*} \\
& \quad=\left(\boldsymbol{\xi}^{T}\right)^{N-1} \boldsymbol{P} \widehat{\boldsymbol{C}}^{T} R^{*}
\end{aligned}
$$

が成り立つので(25)式は

$$
D \widehat{\boldsymbol{B}}^{T}\left[\widehat{\boldsymbol{C}}^{T}, \boldsymbol{\xi}^{T} \widehat{\boldsymbol{C}}^{T},\left(\boldsymbol{\xi}^{T}\right)^{2} \widehat{\boldsymbol{C}}^{T}, \cdots,\left(\boldsymbol{\xi}^{T}\right)^{N-1} \boldsymbol{P} \widehat{\boldsymbol{C}}^{T}\right] \overline{\boldsymbol{R}}(k)
$$

となり，(13) 式の予見フィードフォワード項に一致する. すなわち, 本章で導出した $(k+1)$ から $(k+N)$ ステップ までの未来目標值信号を利用した予見サーボ系は $(k$ $+N+1)$ ステップ以降の目標値信号をすべて $R(k+N)$ と同じ值とみなしていることに相当することがわかる.

\section{3. 最適性の原理を用いる GPC の設計}

ここでは 2 章の結果を利用して, 最適性の原理を用い た GPC システムの誘導を行う。これは Clarke らが提案 している手法とは異なった手法により, GPC システムの 託計を行うものである.

GPC システムにおいて用いられている評価関数 $J_{G}$ は (29)式のようなものである4).

$$
\begin{aligned}
J_{G}= & \sum_{j=N_{1}}^{N}\{R(k+j)-y(k+j)\}^{2} \\
& \left.+\sum_{j=1}^{N U} \rho \Delta u(k+j-1)^{2}\right\}
\end{aligned}
$$

ここで $N$ は最大評価ホライズン, $N_{1}$ は最小評価ホライ ズンそして $N U$ は制御ホライズンと呼ばれている。この とき, $j \geqq N U+1$ で $\Delta u(k+j-1)=0$ と仮定される.(1) 式で表わされた制御対象に対して(29)式の評価関数のも と最適な操作量を求めるものが $\mathrm{GPC}$ である.ここでは, $N_{1}=1$ とし, まず $N=N U$ の場合, 続いて $N \neq N U$ の場 合の設計法を 2 章の結果を用いて述べる.

[1] $N=N U$ のとき

(27) 式の評価関数は

$$
J_{G}=\sum_{j=1}^{N}\left[\{R(k+j)-y(k+j)\}^{2}+\rho \Delta u(k+j-1)^{2}\right]
$$

となる.（30)式の評価関数 $J_{G}$ は (4) 式の評価関数 $J$ で $H=0$ とした場合に相当する。したがってこれを最小に する制御則は， 2 章と同様に最適性の原理を用いて以下 のように与えられる.

$$
\begin{aligned}
\Delta u(k)=- & D(N) \hat{\boldsymbol{B}}^{T} \boldsymbol{S}(N-1) \hat{\boldsymbol{A}} \boldsymbol{x}_{0}(k) \\
+ & D(N) \hat{\boldsymbol{B}}^{T}\left[\hat{\boldsymbol{C}}^{T}, \boldsymbol{\xi}^{T}(N-2) \hat{\boldsymbol{C}}^{T},\right. \\
& \boldsymbol{\xi}^{T}(N-2) \boldsymbol{\xi}^{T}(N-3) \hat{\boldsymbol{C}}^{T}, \cdots, \\
& \left.\boldsymbol{\xi}^{T}(N-2) \cdots \boldsymbol{\xi}^{T}(0) \hat{\boldsymbol{C}}^{T}\right] \overline{\boldsymbol{R}}(k)
\end{aligned}
$$

第 28 巻 第 8 号

ここで $\boldsymbol{D}(N), \boldsymbol{S}(N-1), \boldsymbol{\xi}(N-2), \cdots, \boldsymbol{\xi}(0)$ は, ( 8) $\sim(11)$ 式を

$$
\begin{aligned}
& \boldsymbol{S}(0)=\hat{\boldsymbol{C}}^{T} \hat{\boldsymbol{C}} \\
& D(1)=\left[\rho+\widehat{\boldsymbol{B}}^{T} \boldsymbol{S}(0) \hat{\boldsymbol{B}}\right]^{-1} \\
& \boldsymbol{\Theta}^{T}(0)=\mathbf{0}
\end{aligned}
$$

の境界条件のもとで解いて得られる.

$$
\text { [2] } N \neq N U \text { のとき }
$$

一般に $N U<N$ であり, $j \geqq N U+1$ で $\Delta u(k+j-1)$ $=0$ を強制することになるので ${ }^{2)}$ （29)式の評価関数は

$$
\begin{aligned}
J_{G}= & \sum_{j=1}^{N U}\left[\{R(k+j)-y(k+j)\}^{2}\right. \\
& \left.+\rho \Delta u(k+j-1)^{2}\right] \\
& +\sum_{j=N U+1}^{N}\left[\{R(k+j)-y(k+j)\}^{2}\right. \\
& \left.+\varepsilon \Delta u(k+j-1)^{2}\right]
\end{aligned}
$$

で, $\varepsilon \rightarrow \infty$ とる.このときの制御入力は (31) 式と同じで あるが, $D(N-j)$ とその境界条件は

1) $N-1 \geqq j \geqq N U$ のとき

$$
D(N-j)=\left[\varepsilon+\widehat{\boldsymbol{B}}^{T} \boldsymbol{S}(N-j+1) \hat{\boldsymbol{B}}\right]^{-1}
$$

境界条件 $D(1)=\left[\varepsilon+\widehat{\boldsymbol{B}}^{T} \boldsymbol{S}(0) \hat{\boldsymbol{B}}\right]^{-1}$

2) $N U-1 \geqq j \geqq 0$ のとき

$$
D(N-j)=\left[\rho+\widehat{\boldsymbol{B}}^{T} \boldsymbol{S}(N-j+1) \hat{\boldsymbol{B}}\right]^{-1}
$$

境界条件 $D(N-N U+1)=\left[\rho+\widehat{\boldsymbol{B}}^{T} \boldsymbol{S}(N-N U) \hat{\boldsymbol{B}}\right]^{-1}$ となる。

つぎにここで求めた GPC の設計結果と Clarke らの 手法による GPCの設計結果が一致することを簡単な例 題で示しておく.

[例題]

いま，プラントとして $n=2, m=1, L_{m}=0$ のものを 考え,

$$
\left(1+a_{1} z^{-1}+a_{2} z^{-2}\right) y(k)=\left(b_{0}+b_{1} z^{-1}\right) u(k-1)
$$
とする.ここで $N=N U=2$ としてフィードバック係数 行列 $\boldsymbol{F}_{x}$, 予見フィードフォワード係数行列 $\boldsymbol{F}_{R}$ を求め る.

A） Clarke らの手法による GPC の設計2) 制御入力は

$$
\begin{aligned}
\Delta u(k)= & {\left[\begin{array}{ll}
1 & 0
\end{array}\right]\left(\boldsymbol{G}^{T} \boldsymbol{G}+\rho I\right)^{-1} \boldsymbol{G}^{T}(\overline{\boldsymbol{R}}(k)-\boldsymbol{f}) } \\
= & \boldsymbol{F}_{R} \overline{\boldsymbol{R}}(k)+f_{y 0} y(k)+f_{y 1} y(k-1) \\
& +f_{y 2} y(k-2)+f_{u 1} \Delta u(k-1)
\end{aligned}
$$

となる。ここで, $\boldsymbol{f}$ は Diophantine 方程式を解いて得ら れる現在から過去の $y$ と過去の $u$ に依存する項であり, $G$ はプラントの indicial 応答係数 $g_{0}, g_{1}$ で構成される行 列

$$
\boldsymbol{G}=\left[\begin{array}{ll}
g_{0} & 0 \\
g_{1} & g_{0}
\end{array}\right]
$$

である， $g_{0}, g_{1}$ は(33)式を使って求めると 
江上・土谷・愛田・北森：予見サーボ系の設計と一般化予測制御（GPC）システムについて

$$
\begin{aligned}
& g_{0}=b_{0} \\
& g_{1}=b_{1}+\left(1-a_{1}\right) b_{0}
\end{aligned}
$$

となり，予見フィードフォワード係数行列 $\boldsymbol{F}_{R}$ は

$$
\boldsymbol{F}_{R}=\left[\begin{array}{ll}
1 & 0
\end{array}\right]\left(G^{T} G+\rho I\right)^{-1} G^{T}
$$

$$
\begin{aligned}
& =\frac{\left[\left(\rho+g_{0}^{2}\right) b_{0}, \rho g_{1}\right]}{\rho^{2}+\left(2 g_{0}^{2}+g_{1}^{2}\right) \rho+g_{0}^{4}} \\
& =\frac{\left[\left(\rho+b_{0}^{2}\right) b_{0}, \rho\left\{b_{1}+\left(1-a_{1}\right) b_{0}\right]\right.}{\rho^{2}+d \rho+b_{0}^{4}}
\end{aligned}
$$

$$
d \triangleq 3 b_{0}^{2}+2 b_{0} b_{1}+b_{1}^{2}-a_{1} b_{0}\left(2 b_{0}+2 b_{1}-a_{1} b_{0}\right)
$$

となる.またフィードバック係数行列 $\boldsymbol{F}_{x}=\left[f_{y 0} f_{y 1} f_{y 2}\right.$ $\left.f_{u 1}\right]$ は, 文献 2)の Diophantine 方程式の recursion の手 法に従って

$$
\begin{aligned}
f_{y 0}= & {\left[\left(\rho+b_{0}^{2}\right) b_{0}\left(a_{1}-1\right)\right.} \\
& \left.+\rho\left\{b_{1}+\left(1-a_{1}\right) b_{0}\right\}\left(a_{1}+a_{2}-1-a_{1}^{2}\right)\right] \\
& /\left(\rho^{2}+d \rho+b_{0}^{4}\right) \\
f_{y 1}= & {\left[\left(\rho+b_{0}^{2}\right) b_{0}\left(a_{2}-a_{1}\right)\right.} \\
& \left.+\rho\left\{b_{1}+\left(1-a_{1}\right) b_{0}\right\} a_{1}\left(a_{1}-1-a_{2}\right)\right] \\
& /\left(\rho^{2}+d \rho+b_{0}^{4}\right) \\
f_{y 2}= & {\left[-\left(\rho+b_{0}^{2}\right) b_{0} a_{2}\right.} \\
& \left.+\rho\left\{b_{1}+\left(1-a_{1}\right) b_{0}\right\} a_{2}\left(a_{1}-1\right)\right] \\
& /\left(\rho^{2}+d \rho+b_{0}^{4}\right) \\
f_{u 1}= & {\left[\left(\rho+b_{0}^{2}\right) b_{0 b 1}\right.} \\
& \left.+\rho\left\{b_{1}+\left(1-a_{1}\right) b_{0}\right\}\left(1-a_{1}\right) b_{1}\right] \\
& /\left(\rho^{2}+d \rho+b_{0}^{4}\right)
\end{aligned}
$$

と求まる。

B） 最適性の原理を用いる GPC の設計

(33) 式を状態方程式表現すると（2)式にしたがって

$$
\begin{aligned}
& \tilde{\boldsymbol{A}}=\left[\begin{array}{ccc}
-a_{1} & -a_{2} & b_{1} \\
1 & 0 & 0 \\
0 & 0 & 0
\end{array}\right] \quad \tilde{\boldsymbol{B}}=\left[\begin{array}{c}
b_{0} \\
0 \\
1
\end{array}\right] \\
& \tilde{\boldsymbol{C}}=\left[\begin{array}{lll}
1 & 0 & 0
\end{array}\right]
\end{aligned}
$$

となる。そして拡大系は $(3)$ 式にしたがって

$$
\begin{aligned}
& \hat{\boldsymbol{A}}=\left[\begin{array}{cccc}
1-a_{1}-a_{2} & b_{1} \\
0 & -a_{1}-a_{2} & b_{1} \\
0 & 1 & 0 & 0 \\
0 & 0 & 0 & 0
\end{array}\right] \quad \hat{\boldsymbol{B}}=\left[\begin{array}{c}
b_{0} \\
b_{0} \\
0 \\
1
\end{array}\right]
\end{aligned}
$$

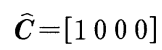

と求まる。以下 3 章 $[1]$ の手順にしたがってつぎのよう に順次求まる。

$$
\begin{aligned}
& \boldsymbol{S}(0)=\widehat{\boldsymbol{C}}^{T} \widehat{\boldsymbol{C}}=\left[\begin{array}{llll}
1 & 0 & 0 & 0 \\
0 & 0 & 0 & 0 \\
0 & 0 & 0 & 0 \\
0 & 0 & 0 & 0
\end{array}\right] \\
& D(1)=\left[\rho+\widehat{\boldsymbol{B}}^{T} \boldsymbol{S}(0) \hat{\boldsymbol{B}}\right]^{-1}=\frac{1}{\rho+b_{0}^{2}} \\
& \boldsymbol{S}(1)=\hat{\boldsymbol{A}}^{T} \boldsymbol{S}(0) \hat{\boldsymbol{A}}-\hat{\boldsymbol{A}}^{T} \boldsymbol{S}(0) \hat{\boldsymbol{B}} D(1) \hat{\boldsymbol{B}}^{T} \boldsymbol{S}(0) \hat{\boldsymbol{A}}
\end{aligned}
$$

$$
\begin{aligned}
& +\widehat{\boldsymbol{C}}^{T} \widehat{\boldsymbol{C}} \\
& =\frac{\rho}{\rho+b_{0}^{2}} \\
& \times\left[\begin{array}{cccc}
2+b_{0}^{2} / \rho & -a_{1} & -a_{2} & b_{1} \\
-a_{1} & a_{1}^{2} & a_{1} a_{2} & -a_{1} b_{1} \\
-a_{2} & a_{1} a_{2} & a_{2}^{2} & -a_{2} b_{1} \\
b_{1} & -a_{1} b_{1} & -a_{2} b_{1} & b_{1}^{2}
\end{array}\right] \\
& D(2)=\left[\rho+\widehat{\boldsymbol{B}}^{T} \boldsymbol{S}(1) \hat{\boldsymbol{B}}\right]^{-1} \\
& =\frac{\rho+b_{0}^{2}}{\rho^{2}+d \rho+b_{0}^{4}} \\
& \boldsymbol{\xi}(0)=\hat{\boldsymbol{A}}-\hat{\boldsymbol{B}} D(1) \hat{\boldsymbol{B}}^{T} \boldsymbol{S}(0) \hat{\boldsymbol{A}} \\
& =\frac{\rho}{\rho+b_{0}^{2}}\left[\begin{array}{cccc}
1 & -a_{1} & -a_{2} & b_{1} \\
\times & \times & \times & \times \\
\times & \times & \times & \times \\
\times & \times & \times & \times
\end{array}\right]
\end{aligned}
$$

したがって予見フィードフォワード係数行列 $\boldsymbol{F}_{R}$ は

$$
\begin{aligned}
\boldsymbol{F}_{R} & =D(2) \hat{\boldsymbol{B}}^{T}\left[\hat{\boldsymbol{C}}^{T} \boldsymbol{\xi}^{T}(0) \hat{\boldsymbol{C}}^{T}\right] \\
& =\frac{\left[\left(\rho+b_{0}^{2}\right) b_{0}, \rho\left\{b_{1}+\left(1-a_{1}\right) b_{0}\right]\right.}{\rho^{2}+d \rho+b_{0}^{4}}
\end{aligned}
$$

となり,フィードバック係数行列 $\boldsymbol{F}_{x}$ は

$$
\begin{aligned}
\boldsymbol{F}_{x} & =-D(2) \hat{\boldsymbol{B}}^{T} \boldsymbol{S}(1) \hat{\boldsymbol{A}} \\
& =\left[\begin{array}{llll}
f_{y 0}+f_{y 1}+f_{y 2} & -f_{y 1}-f_{y 2} & -f_{y 2} & f_{u 1}
\end{array}\right]
\end{aligned}
$$

となって A)の結果と一致する。

\section{4. 予見サーボ系の特徵}

2 章で提案した予見サーボ系は, Riccati 方程式の定 常解を用いてフィードバック係数行列および予見フィー ドフォワード係数行列を設計しているためつぎのような 特徴がある。

[a ］ GPCでは, $N$ および $N U$ の選択によって, (31) 式のフィードバック係数行列 $\boldsymbol{F}_{x}$, 予見フィードフォワー ド係数行列 $\boldsymbol{F}_{R}$ が複雑に変化するが, 予見サーボ系では (13) 式の $\boldsymbol{F}_{x}$ が $N$ に依存しないので, フィードバック特 性は評価関数の重み $\rho$ のによって決まる. 目標值信号 の予見フィードフォワード効果のみが $N$ に依存し $N$ は 予見ステップ数とみなせる。

[b]予見サーボ系では $\boldsymbol{\xi}$ は常に安定行列となり, $\xi^{N-1} \rightarrow 0(N \rightarrow \infty)$ となる. $R(k+N)$ の予見フィードフォ ワード係数は $\left(\boldsymbol{\xi}^{T}\right)^{N-1}$ に比例するので, $N \rightarrow \infty て ゙$ 漸近的 に零になる.また評価関数の重み $\rho$ が小さくなれば $\boldsymbol{\xi} の$ 固有值も小さくなるので, $N$ は小さくてよく, その度合 は $\xi$ の固有值の大きさに依存する7).これに対して GPC システムでは, $N$ は制御系のフィードバック特性にも関 係してくるので, 予見サーボ系の場合のように制御系と の明確な関係は述べられず, $N$ は $N \geqq 2(n+L)-1$ とし, 実際にはプラントの立ち上がり時間にとるといわれてい $ろ^{4)}$. 
[c] 予見サーボ系では $N$ に関係なく制御系は常に 安定となり, 制御系の $\rho \rightarrow 0$ での漸近特性も求められて (る ${ }^{8)}$.

ただし， $N=N U$ で，これらが大きくなると GPCのフ イードバック特性は予見サーボ系のものに漸近する。こ れは (4)式の評価関数 $J$ を用いて計算されたフィード バック係数行列 $\boldsymbol{F}_{x}$ （あるいは $\boldsymbol{F}_{y}, \boldsymbol{F}_{u}$ ）は, 2.3 より

$$
\begin{aligned}
J_{\infty}= & \sum_{j=1}^{\infty}\left[\left\{\boldsymbol{R}_{0}(k+j)-\boldsymbol{x}_{0}(k+j)\right\}^{T} \widehat{\boldsymbol{C}}^{T} \widehat{\boldsymbol{C}}\right. \\
& \left.\times\left\{\boldsymbol{R}_{0}(k+j)-\boldsymbol{x}_{0}(k+j)\right\}+\rho \Delta u(k+j-1)^{2}\right]
\end{aligned}
$$

を用いて設計されたものと同じになるが，(29)式の評価 関数 $J_{G}$ で $N \rightarrow \infty$ とすると $J_{\infty}$ に漸近することから明ら かとなる。

[d] GPC システムはプラントのパラメータとステ ップ応答係数を用いて制御系が設計できる.またパラメ ータをオンラインで同定するセルフチューニング制御に 適している。一方, 予見サーボ系の場合, セルフチュー ニング制御を行う場合には GPC システムに比べてある 程度計算時間がかかると予想される。

\section{6. 予見サーボ系のシミュレーション}

2 章で提案したARMAX モデルに対する予見サーボ 系を DC モー夕速度制御へ適用したシミュレーション結 果を示す.用いた DC モータの定格值は $1.5 \mathrm{~kW}, 100 \mathrm{~V}$, $18.5 \mathrm{~A}, 1500 \mathrm{rpm}$ であり, サンプリング周期は $10 \mathrm{~ms}$ と している.このシステムの ARMAX モデルは(31) 式と 同様であり,

$$
\begin{aligned}
(1 & \left.+a_{1} z^{-1}+a_{2} z^{-2}\right) y(k) \\
& =\left(b_{0}+b_{1} z^{-1}\right) u(k-1)+d(k)
\end{aligned}
$$

となる．ただし， $y(k)=\omega_{r}(k)$ (回転速度), $u(k)=v_{a}(k)$ (電機子電圧) である. またこのシステムのパラメー夕值 は以下のようである.

$$
\begin{array}{ll}
a_{1}=-1.55 & a_{2}=5.73 \times 10^{-1} \\
b_{0}=3.59 \times 10^{-3} & b_{1}=2.98 \times 10^{-3}
\end{array}
$$

Fig. 3 にこのシミュレーション結果を示す.ここでは $\rho=10.0$ とし, $d(k)=0$ としている.また電機子電流 $i_{a}(k)$ の応答も参考までに示してある. ( a ), ( b ), ( c ) はそれぞれ $N=2, N=20, N=40$ の場合のステップ状目 標值変化に対するシステムの応答を示したものである. $N$ を大きくするにつれて, 目標值の先だって回転速度 $y(k)$ が変化し, 入力 $u(k)$ が穏やかに変化していること がわかる．また $R(k+40)$ に対する予見フィードフォワ 一ド係数は $R(k+1)$ の係数の $17 \%$ 程度となっており, $N$ をこれ以上大きくしても応答はほとんど変わらないもの となっている.

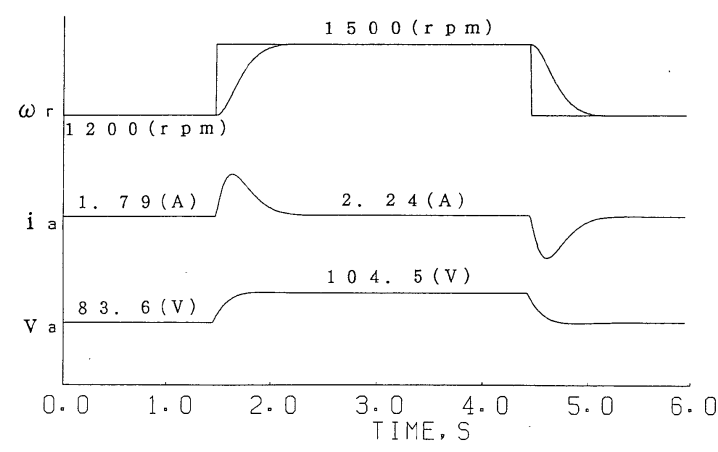

(a) $\quad N=2$

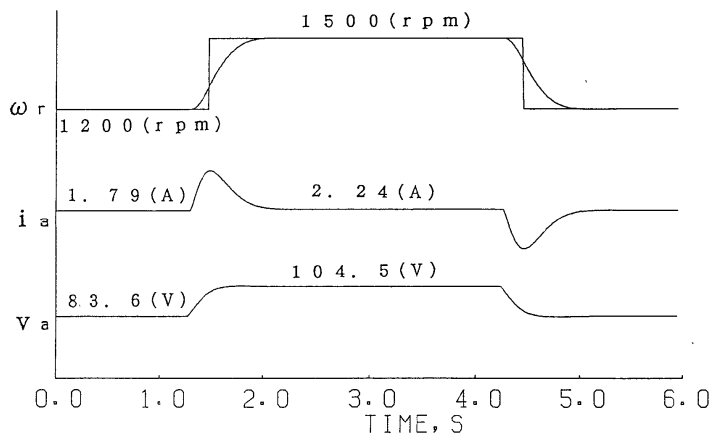

(b) $N=20$

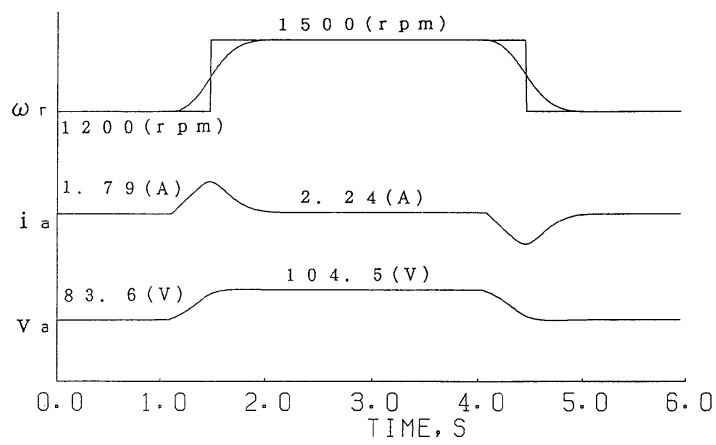

(c) $N=40$

Fig. 3 System response of preview servo system

\section{7.あとがき}

CARIMA モデルに対する予見サーボ系の設計法を提 案した。この予見サーボ系は常に安定な制御系となる特 徵をもっている。ここで提案した予見サーボ系の設計法 は, ランプ状目標入力の場合や多入出力系の場合にも容 易に拡張できるものである.

つぎに最適性の原理を用いて GPC システムが設計で きることも示した.これによって, 制御ホライズン $N U$ と制御系の性質との関係を考察できると考えられるが, これは今後の課題としたい. 
また本論文では $d(k)=\eta(k) / \Delta$ としたが文献 3)，4）の ように $d(k)=C\left(z^{-1}\right) \eta(k) / \Delta て ゙$ 表わされているときの設 計法についても今後の課題としたい.さらに $\mathrm{MAC}$, DMCアルゴリズムと予見サーボ系の関係を明らかにす ることや，オートチューニングに適した予見サーボ系の アルゴリズムの開発なども興味のある問題と思われる.

\section{参考文 献}

1) 西谷紘一：モデル予測制御の応用，計測と制御，2811 (1989)

2) D. W. Clarke, C. Mohtadi and P.S. Tuffs: Generalized Predictive Control-Part I. The Basic Algorithm, Automatica, 23-2 (1987)

3) D. W. Clarke, C. Mohtadi and P.S. Tuffs: Generalized Predictive Control-Part II. Extensions and Interpretations, Automatica, 23-2 (1987)

4) D. W. Clarke and C. Mohtadi : Properties of Generalized Predictive Control, Automatica, 25-6 (1989)

5）土谷, 江上：多入力多出力ロバスト予見制御系設計法, 計 測自動制御学会論文集, 22-8 (1986)

6) T. Katayama, T. Ohki, T. Inoue and T. Kato: Design of an Optimal Controller for a Discrete-Time System Subject to Previewable Demand, Int. J. of Control, 41-3, 677/699 (1985)

7）江上, 品田, 土谷：予見フィードフォワード補償を含む部 分状態フィードパック制御系構成法, 計測自動制御学会論 文集，23-12（1987）

8）愛田, 北森：最適予見制御と最小 2 乗スムージングの関係 および平滑化逆システムの一構成法, 計測自動制御学会論 文集，25-4（1989）

\section{《付録》}

本子見サーボ系の制御則が文献 6 ) の子見サーボ系の 制御則と等価になることの証明。

文献 6 ) の設計法では， $N$ 時点未来までの目標值が予 見できるものとし $R(k)=0(k=0,-1, \cdots), \Delta R(k+i)(i$ $=N+1, \cdots)$ と仮定する。

この方法は制御則

$$
\Delta u(k)=\boldsymbol{G}_{x}\left[\begin{array}{c}
e(k) \\
\Delta \widetilde{\boldsymbol{x}}(k)
\end{array}\right]+\boldsymbol{G}_{R} \Delta \overline{\boldsymbol{R}}(k)
$$

のフィードバック係数行列 $G_{x}$ 抢よび予見フィードフォ ワード係数行列 $G_{R}$ を拡大系

$$
\begin{aligned}
{\left[\begin{array}{c}
e(i+1) \\
\Delta \tilde{\boldsymbol{x}}(i+1)
\end{array}\right]=} & \tilde{\boldsymbol{A}}\left[\begin{array}{c}
e(i) \\
\Delta \tilde{\boldsymbol{x}}(i)
\end{array}\right]+\tilde{\boldsymbol{B}} \Delta u(i) \\
& +\left[\begin{array}{c}
-1 \\
0
\end{array}\right] \Delta R(i+1)
\end{aligned}
$$

の拘束のもとで，(15) 式の評価関数 $J_{0}$ を最小にするよう に設計するものである。このとき設計結果は

$$
\boldsymbol{G}_{x}=-D \widetilde{\boldsymbol{B}}^{T} \boldsymbol{P} \hat{\boldsymbol{A}} \boldsymbol{x}_{0}(k)
$$

$$
\begin{aligned}
\boldsymbol{G}_{R}= & D \widehat{\boldsymbol{B}}^{T}\left[\boldsymbol{P} \hat{\boldsymbol{C}}^{T}, \boldsymbol{\xi}^{T} \boldsymbol{P} \hat{\boldsymbol{C}}^{T},\left(\boldsymbol{\xi}^{T}\right)^{2} \boldsymbol{P} \widehat{\boldsymbol{C}}^{T}, \cdots,\right. \\
& \left.\left(\boldsymbol{\xi}^{T}\right)^{N-1} \boldsymbol{P} \hat{\boldsymbol{C}}^{T}\right]
\end{aligned}
$$

となる. (13) 式と (A 3) 式より $\boldsymbol{F}_{x}=\boldsymbol{G}_{x}$ となりフィード バック係数行列は一致する。一方，(A 1) 式の予見制御部 を $\Delta u_{P}(k)$ とすると $(\mathrm{A} 4)$ 式から

$$
\begin{aligned}
\Delta u_{P}(k)= & \boldsymbol{G}_{R} \Delta \bar{R}(k) \\
=- & D \widehat{\boldsymbol{B}}^{T} \boldsymbol{P} \hat{\boldsymbol{C}}^{T} R(k) \\
+ & D \widehat{\boldsymbol{B}}^{T}\left[\left(\boldsymbol{I}-\boldsymbol{\xi}^{T}\right) \boldsymbol{P} \widehat{\boldsymbol{C}}^{T}, \boldsymbol{\xi}^{T}\left(\boldsymbol{I}-\boldsymbol{\xi}^{T}\right) \boldsymbol{P} \widehat{\boldsymbol{C}}^{T},\right. \\
& \cdots,\left(\boldsymbol{\xi}^{T}\right)^{N-2}\left(\boldsymbol{I}-\boldsymbol{\xi}^{T}\right) \boldsymbol{P} \widehat{\boldsymbol{C}}^{T}, \\
& \left.\left(\boldsymbol{\xi}^{T}\right)^{N-1} \boldsymbol{P} \widehat{\boldsymbol{C}}^{T}\right] \overline{\boldsymbol{R}}(k)
\end{aligned}
$$

となる、ここで(21)式から

$$
\left(\boldsymbol{I}-\boldsymbol{\xi}^{T}\right) \boldsymbol{P} \hat{\boldsymbol{C}}^{T}=\hat{\boldsymbol{C}}^{T}
$$

の関係が成り立ち， $R(k)=0$ の仮定と $(\Lambda 6)$ 式を，(A 5) 式に用いて, (13) 式と比較すると, $\boldsymbol{F}_{R}=\boldsymbol{G}_{R} \Delta$ となり, 予 見フィードフォワード係数行列も一致する.

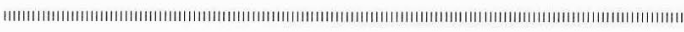

$$
\text { [著 者 紹 介] }
$$

\section{江上正 (正会員)}

1982 年, 北海道大学工学部電気工学科卒 業. 86 年同大学院工学研究科博士課程修 了. 同年神奈川大学工学部機械工学科専任 講師, 90 年同助教授, 現在に至る. ゙ィジ タル制御理論とその応用に関する研究に従 事 (工学博士).

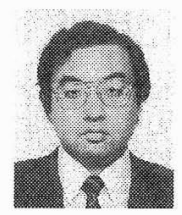

\section{土 谷 武 士 (正会員)}

1963 年, 北海道大学工学部電気工学科卒 業. 65 年同大学院工学研究科修士課程修 了. その後北海道大学工学部講師, 助教授 を経て現在同教授.制御工学, ロボット工 学，パワーエレクトロニクスなどの研究に 彷事 (工学博士).

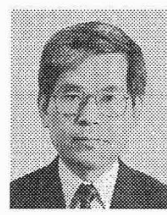

\section{愛田一雄（正会員）}

1961 年, 金沢大学工学部機械工学科卒 業. (株)古河電気工業を経て 65 年新潟大学 工学部精密工学科助手. 現在機械システム 工学科助教授. 制御系の設計法に関する研 究に従事. 74 年計測自動制御学会論文賞受 賞 (工学博士).

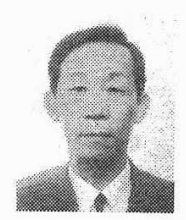

\section{北 森 俊 行 (正会員)}

(Vol. 28, No. 4 参照) 